\title{
NEGOCIAÇÃO NA CONTRATAÇÃO DE PRESTADORES DE SERVIÇOS: ESTUDO DE CASO EM UMA EMPRESA DE DISTRIBUIÇÃO DE ENERGIA
}

\author{
Miguel Soares de Souza, Érika Mayumi Kato Cruz
}

Universidade do Oeste Paulista - UNOESTE, Presidente Prudente, SP.

\section{RESUMO}

O presente estudo analisou o processo de negociação para contratação de serviços terceirizados de uma empresa atuante no ramo de distribuição de energia. Foram abordados desde os fatores de preparação e planejamento, até o processo de negociação em si, incluindo a existência de conflitos, importância da negociação para a organização e seus gerentes - na busca por resultados satisfatórios - e a utilização de técnicas básicas de negociação. Para tanto, o artigo contempla um estudo de caso, com coleta de dados por meio de entrevista. Trata-se, assim, de uma pesquisa qualitativa descritiva, com foco na coordenação de contratação de serviços da empresa. Os resultados apontam que a empresa considera muito importante os processos de negociação, no entanto, não há uma padronização de ação dos negociadores. Nota-se que eles buscam agir conforme suas experiências e conhecimentos, sempre com vista a manter um bom relacionamento com as prestadoras de serviço.

Palavras-chave: Negociação. Processo de Negociação. Contratação de Serviços Terceirizados.

\section{NEGOTIATION IN CONTRACTING SERVICE PROVIDERS: CASE STUDY IN AN ENERGY DISTRIBUTION COMPANY}

\begin{abstract}
The presente study analyzed the negotiation process for contracting third party services of a energy distribution company. Were addressed from the preparation and planning factors to the negotiation process itself, including the existence of conflicts, the importance of negotiation for the organization and its managers - looking for satisfactory results - and the use of basic negotiation techniques. For this, the article contemplates a case study, with data collection through interview. Therefore, It's a descriptive qualitative research, focusing on the coordination of contracting services of the company.
\end{abstract} The results indicate that the company considers the negotiation processes to be very important, however, there is no standardization of negotiators' action. It is noted that they seek to act according to their experiences and knowledge, always with a view to maintaining a good relationship with service providers.

Keywords: Negotiation. Negotiation Process. Contracting of Third Party Services.

\section{INTRODUÇÃO}

Diversas questões são levantadas quando o assunto é otimizar resultados em uma organização, com destaque neste estudo para as negociações.

Baseando-se nos estudos de Fisher, Ury e Patton (2005, p. 15), nota-se que, "queira ou não, você é um negociador [ou seja] a negociação é uma verdade da vida". Nesta mesma linha, Vanin (2013) afirma que as pessoas estão sempre negociando posições, podendo envolver valores monetários ou pessoais, em qualquer cenário.

No ambiente empresarial, a complexidade e dinamicidade do tema faz com que, segundo Martinelli (2002, p. xvii), a negociação venha assumindo cada vez mais diversas classificações de 
estilos e de perfis de negociadores. Martinelli (2002, p. xix) aponta ainda para o fato de que, no momento negociar, deve-se buscar uma visão sistêmica do problema, com o intuito de abrir uma margem para negócios e relações futuras.

Logo, com vista a compreender melhor como se dá o processo de negociação no ambiente empresarial, o referido artigo tem o intuito de analisar o processo de negociação para contratação de serviços terceirizados de uma empresa atuante no ramo de distribuição de energia, desde a etapa de preparação até o uso de técnicas básicas de negociação.

As equipes muitas vezes podem não utilizar as técnicas de preparação e negociação da forma mais eficiente, porém a hipótese é de que a equipe da área de contratação de serviços terceirizados é capacitada e possui as habilidades e competências necessárias para que seja possível otimizar as negociações realizadas para a organização.

Para tanto, o estudo cumpre com os objetivos específicos a seguir: caracterizar a empresa objeto de estudo, descrever como ocorre o processo de contratação de serviços terceirizados dessa empresa, descrever a importância da negociação para os envolvidos nos processos em análise, verificar a existência de preparação da equipe para o processo de negociação, constatar a existência de conflitos ao longo do processo, apontar a utilização de técnicas de negociação nos processos de contratação levantados.

\section{MATERIAIS E MÉTODOS}

Para descrever o objeto de estudo com mais profundidade, optou-se pela pesquisa qualitativa que, segundo Mascarenhas (2012), é muito comum em estudos sobre o comportamento de um indivíduo ou grupo.

A pesquisa descritiva, por sua vez, estuda as propriedades de um grupo e sua realidade, tendo como foco principal a identificação das representações sociais e as características de indivíduos e grupos (CERVO, BERVIAN e SILVA, 2007).

A coleta dos dados ocorreu por meio de entrevista que, segundo Goode e Hatt (apud LAKATOS e MARCONI, 2010, p. 179), "consiste no desenvolvimento de precisão, focalização, fidedignidade e validade de certo ato social como a conversação". O sujeito da pesquisa foi o coordenador de contratação de serviços terceirizados da empresa.

Os dados coletados foram analisados por meio de comparação com a teoria sobre o tema com foco nas circunstâncias em que os negociadores negociam, a dinamicidade das negociações e os fatores envolvidos (uso de técnicas, aplicação de políticas de negociação, aspectos como preço, prazo e qualidade, bem como existência de conflitos).

\section{A NEGOCIAÇÃO E O CONTEXTO ORGANIZACIONAL}

A negociação pode ser definida, na visão de Cohen (apud MARTINELLI, 2002, p. 20), como "[...] a utilização da informação e do poder, buscando influenciar o comportamento em uma rede de tensão". Na visão de Fisher e Ury (apud MARTINELLI, 2002, p. 22), trata-se de "...um processo bilateral de comunicação com o objetivo de alcançar uma decisão compartilhada".

De forma complementar, Thompson (2009, p. 03) afirma que há cinco razões principais que justificam a importância das habilidades em negociação para executivos, líderes e gerentes: a natureza dinâmica dos negócios, resultando na adoção de estruturas descentralizadas para enfrentar desafios organizacionais. A interdependência, seja entre pessoas ou unidades de uma ou mais empresas. A concorrência, fator este inevitável nas empresas e cada dia mais crescente. A era da informação, que vem a proporcionar maior comunicação dinâmica para tomada de decisões. E a globalização, que impõe aos gerentes ter habilidades genéricas o bastante para serem utilizadas em diferentes contextos, e especializadas, o suficiente para fornecer estratégias que abordem situações mais particulares. 
Nota-se que as negociações são essenciais no contexto organizacional e impactam em todos os níveis das empresas.

Buscando uma análise geral deste cenário globalizado, é possível observar que negociar é uma competência necessária a todos os profissionais, e tal habilidade permite que pessoas e organizações atendam suas necessidades e relacionamentos em escala nacional e global (COSTA, 2013).

Cabe destacar que nos processos de negociação sempre haverá o conflito (THOMPSON, 2009).

Thomas (apud GARBELINI, 2016, p. 21), nos traz a definição de que "o conflito é o processo que começa quando uma das partes percebe que a outra parte o afetou de forma negativa, ou que irá afetar de igual forma ".

Chiavenato (apud GARBELINI, 2016, p. 21) tem a concepção de que:

a palavra conflito está ligada a [sic] discórdia, divergência, dissonância, controvérsia ou antagonismo [...], o conflito existe quando uma das partes [...] interfere na parte que procura atingir seus objetivos. A interferência pode ser ativa - mediante ação para provocar obstáculos, bloqueios ou impedimentos - ou passiva - mediante omissão.

Nesse contexto, pode-se afirmar que num ambiente de negociação o conflito se faz presente. Sendo assim, um ponto importante a ser levado em consideração é a forma da solução de conflitos de forma estratégica, e para isso existem certos tipos de negociação.

Dentre os tipos de negociação estão a distributiva e a integrativa.

O conceito de negociação distributiva é abordado por Fisher, Ury e Patton (2005) como barganha posicional, na qual o negociador procura aumentar a qualquer custo um acordo que lhe seja favorável, buscando obter sempre uma vantagem da outra parte.

Os mesmos autores abordam a negociação integrativa, por sua vez, como a ação da busca pelo ganho mútuo do negócio, afim de que ambas as partes tenham seus principais interesses atendidos.

Porém, para Thompson (2009, p. 13), “o trabalho que você desenvolve antes da negociação traz uma recompensa substancial quando você finalmente se vê sentado na mesa de negociações “.

Ainda na visão de Thompson (2009), a preparação efetiva é aquela que possui as características de auto avaliação, que trata-se de avaliar fatores como a MASA, ponto de reserva e ZOPA. Avaliação das partes envolvidas, afim de verificar quem está do outro lado da mesa. E a avaliação do cenário, a qual deve-se analisar o tempo da negociação, seus recursos, legalidade, entre outros fatores.

Nota-se que existem algumas ferramentas que se destacam no processo de negociação, a saber: a verificação e análise da MAANA ou MASA, do ponto de reserva e do ZAP ou ZOPA.

A MAANA ou MASA significa a melhor alternativa sem acordo, isto é, a ação a ser seguida caso não se chegue a um acordo na negociação (WATKINS, 2007). Consiste na ação que o indivíduo irá tomar caso a negociação não atenda suas expectativas, tratando-se de um conceito dinâmico. Seria um plano B.

Conhecer a MASA do outro lado também é fundamental, afim de comparar se esta é melhor que a sua e também até que ponto o opositor irá se dispor naquela negociação (WATKINS, 2005).

Outro item de extrema relevância para uma mesa de negociação é o ponto de reserva que, segundo Watkins (2005, p. 38), é definido como "[...] o menor ponto favorável que alguém aceita um acordo". Ou seja, o valor máximo ou mínimo que um indivíduo pode aceitar pagar por algo, ou moralmente falando. 
Neste ponto, o negociador deve analisar todas as possibilidades sobre a situação, os acordos máximos e mínimos (THOMPSON, 2009).

Thompson (2009, p.16) ainda nos diz que "o ponto de reserva não é determinado pelo que o negociador deseja e espera conseguir, mas sim pelo que sua MASA representa". Ou seja, quando se tem um plano $B$ bem definido, o indivíduo tem a capacidade de mensurar o quanto é possível ser aceito na negociação.

Deve-se considerar também, o ponto de reserva da outra parte, ou seja, a ZAP (Zona de Acordo Possível) ou ZOPA.

Para Watkins (2005, p. 39) a ZAP ou ZOPA é "a área ou faixa dentro da qual pode-se chegar a um consenso que satisfaça ambas as partes. Em outras palavras, é o conjunto de acordos capazes de agradar aos dois lados". O conceito se refere, assim, ao intervalo entre os pontos de reserva das partes envolvidas.

Se os itens citados acima são projetados de forma detalhada e o acordo final estiver localizado entre estes dois pontos significa então que há grande possibilidade de ambas as partes terem saído satisfeitas da negociação.

\section{RESULTADOS E DISCUSSÃO}

A empresa estudada está localizada no interior do estado de São Paulo e possui filiais em diversas localidades do Brasil. A organização possui uma equipe dedicada a contratação de serviços terceirizados, tais como: serviços de limpeza e conservação, manutenções de rede elétrica em geral e construções para projetos específicos.

As demandas para contratação de serviços são requisitadas e aprovadas por diretores, e a partir deste momento se iniciam as negociações na busca pelo melhor prestador para o serviço solicitado.

As negociações se iniciam encaminhando o projeto para ao menos três fornecedores diferentes que se interessem na concorrência, solicitando o envio da primeira proposta, contendo aspectos como preço, prazo e qualidade.

Em paralelo a este processo, os candidatos a prestação do serviço são avaliados pela Central de Cadastro de Fornecedores, apresentando documentos que comprovem aspectos como nível de qualidade, inexistência de inadimplência, entre outros. Outro passo de suma importância nesta fase é a validação técnica, isto é, o aceite da área solicitante quanto a proposta dos possíveis fornecedores.

Após primeira proposta recebida, o próximo passo são as negociações via telefone para detalhar aspectos de prazo, tempo de contrato e preço.

São realizadas, no mínimo três rodadas de negociação, afim de que o serviço seja contratado pelo menor valor possível.

A análise do processo de negociação da empresa permite afirmar que esta considera as negociações importantes para o alcance de resultados. A negociação, assim, é vista como uma ferramenta que permite que o colaborador tenha a possibilidade de criar oportunidades para a obtenção de ganhos em diversos aspectos, apontados pela literatura como relacionamento, redução de custos, logística, entre outros pontos.

Outro fator bastante relevante observado na teoria é a preparação prévia às negociações. Nesse ponto, apontamentos do entrevistado mostram que, no caso da empresa em questão, atualmente não há uma preparação antecipada para se iniciar os processos de negociação para contratação de um serviço, seja ele qual for. No entanto, isso se dá pela especialidade da equipe que já possui experiência com tais processos.

Apesar disso, foi possível notar aspectos de preparação no momento inicial das negociações da empresa em que fatores como inflação e preços de contratações anteriores (se está aderente ao mercado ou a contratos anteriores) são considerados. 
Com relação aos conflitos, foi possível notar que os interesses da organização são basicamente o ganho no preço, de forma que sejam realizados os investimentos e manutenções necessárias ao menor custo possível. Outro fator importante que gera conflito nas contratações é o prazo de execução e de entrega do serviço.

No que tange a equipe, o entrevistado afirma que esta tem capacitação e conhecimento das técnicas de negociação. Os membros da equipe têm total autonomia de utilizar ou não as técnicas, sendo que, existem membros que as utilizam e outros que preferem não utilizar, a fim de "levar o processo de forma mais natural", segundo palavras do entrevistado.

Por fim, nota-se que as negociações fazem parte do cotidiano da empresa, no entanto, a experiência da equipe tem possibilitado um processo de negociação simplificado, desde a preparação até o ato da negociação em si, e isso se dá especialmente pela similaridade dos contratos negociados. No que tange aos conflitos, eles existem principalmente quando se negocia preço e prazo, mas na resolução destes busca-se manter o bom relacionamento com a outra parte. As técnicas de negociação também não são tão comuns neste ambiente, talvez novamente pela similaridade e frequência dos termos negociados e a busca pelo bom relacionamento, mesmo assim, quando há possibilidade de uso de técnicas fica a cargo do negociador escolher por utilizálas ou não.

\section{CONCLUSÕES}

O presente estudo propôs analisar o processo de negociação de uma empresa que contrata serviços terceirizados, com foco nos aspectos de preparação, existência de conflitos e uso de técnicas para os atos de negociação.

Assim, relacionando a teoria com o estudo apresentado em entrevista, pode-se verificar pontos em comum como a autonomia dos negociadores para concluir e concretizar os negócios solicitados, a utilização de dados sólidos de mercado, as referências com processos de contratação anteriores e o uso de técnicas de negociação quando necessárias.

A não percepção de um padrão no uso das técnicas de negociação poderia, segundo a teoria, comprometer a otimização efetiva do processo. Porém, o fato de cada negociador poder utilizar as técnicas de acordo com cada situação, se adaptando da melhor forma para negociar tipos de serviço diferentes, proporciona maior autonomia na busca por resultados.

Pode-se verificar então que de uma forma mais regrada ou de maneira mais dinâmica as negociações são importantes para o alcance de resultados da empresa, fator este evidenciado tanto nos estudos teóricos apresentados, quanto no estudo de caso proposto. As técnicas otimizam as negociações e permitem que o indivíduo tenha um suporte maior para si no momento de negociar, mas fica a cargo do negociador saber quando utilizá-las para alcançar seus objetivos da negociação.

As negociações, sejam em grandes corporações ou pequenas empresas, são de extrema relevância no ambiente competitivo, sendo que, dependendo do nível do negócio e da abrangência deste, pode se tornar um fator crítico de sucesso tanto para seu planejamento quanto para sua manutenção no mercado.

Pode-se afirmar que o estudo contribui para conhecer melhor os aspectos de negociação envolvidos na contratação de serviços terceirizados de uma empresa de distribuição de energia elétrica e trouxe contribuições importantes para estudos futuros, especialmente no que tange ao ganho de experiência com processos de negociação e a simplificação do modelo de negociação com base nesse ganho de experiência. Também, possibilita refletir sobre a pertinência do uso de técnicas de negociação racionais em mesas de negociação e a importância da manutenção de relacionamentos para o alcance dos objetivos empresariais.

\section{REFERÊNCIAS BIBLIOGRÁFICAS}


CERVO, A. et al. Metodologia Científica. 6 Ed. São Paulo: Pearson Prentice Hall, 2007.

FISHER, R; URY, W; PATTON, B. Como chegar ao sim: A negociação de acordos sem concessões. 2 ed. Rio de Janeiro: Imago, 2005.

GARBELINI, V. Negociação e Conflitos. 1ำ ed. Curitiba: InterSaberes, 2016.

LAKATOS, E. MARCONI, M. Fundamentos da Metodologia Científica. 7. Ed. São Paulo: Atlas, 2010.

MARTINELLI, D. Negociação Empresarial: enfoque sistêmico e visão estratégica. 1 ํe. ed. São Paulo: Editora Manole Ltda, 2002.

MASCARENHAS, S. Metodologia Científica. São Paulo: Pearson Education do Brasil, 2012.

THOMPSON, L. O negociador. 3 ed. São Paulo: Pearson Prentice Hall, 2009.

VANIN, J. Processos da Negociação. 1o ed. Curitiba: InterSaberes, 2013.

WATKINS, M. Negociação. 4o ed. Rio de Janeiro: Record, 2007.

YOUTUBE. Willian Ury - Como chegar ao sim parte 1 . Disponível em: <https://www.youtube.com/watch?v=wdvyk87szjy\&t=9s>. Acesso em: 23 abr. 2017.

YOUTUBE. Willian Ury: 0 caminho do "não" e do "sim". Disponível em: <https://www.youtube.com/watch?v=hc6yi_ftono\&t=280s>. Acesso em: 23 abr. 2017. 